\title{
Reducing alcohol-related violence and improving community safety: the Alcohol Linking Program
}

\author{
John H. Wiggers \\ On behalf of the Alcohol Linking Program team \\ Hunter New England Population Health, Hunter New England \\ Health Service \\ School of Medicine and Public Health, University of Newcastle \\ Email:john.wiggers@hnehealth.nsw.gov.au
}

\begin{abstract}
Harm associated with the consumption of alcohol on licensed premises is an issue of increasing community concern. This paper reports on a decade-long research initiative that involved the development and implementation of police systems designed to enhance identification of, and police capacity to respond to, premises suggested to be associated with such harms. The outcomes of the Alcohol Linking Program demonstrate enhanced information regarding the occurrence and characteristics of alcohol-related incidents; there are more than 34000 such incidents each year in rural and regional NSW. Evaluation of the impact of an educational intervention demonstrated reductions of about $15 \%$ in the number of alcohol-related incidents linked with such premises. The Program has subsequently been adopted into routine practice on a system-wide basis by the NSW Police and New Zealand Police. Opportunities exist for public health practitioners to contribute to reducing alcohol-related harm in the community through the development of equivalent surveillance systems in emergency departments, monitoring licencee compliance with the Liquor Act, and through injury prevention, health promotion and drug and alcohol practitioners enhancing the capacity of licencees to serve alcohol responsibly.
\end{abstract}

Alcohol-related violence is a significant cause of harm in most countries. ${ }^{1}$ Australian studies suggest that incidents of assault, domestic violence, unintentional injuries and traffic accidents account for $68 \%$ of all alcohol-related hospitalisations and $54 \%$ of all alcohol-related deaths, highlighting the significance of the acute effects of alcohol intoxication. ${ }^{2}$

Alcohol-related harms are associated with a variety of individual and environmental determinants. ${ }^{1}$ Substantial acute alcohol-related harm is associated with the excessive consumption of alcohol on licensed premises. ${ }^{1}$ In Australia, almost half of all alcohol is sold, and approximately $30 \%$ consumed, on licensed premises. ${ }^{3,4}$ However, more than half of all drivers who are charged with drinkdriving have consumed alcohol on licensed premises before the incident, ${ }^{4}$ and $60 \%$ of all alcohol-related incidents attended by police occur on or within sight of a licensed premises. ${ }^{5}$

Despite data suggesting an association between alcohol consumption and harm, understanding of the extent of alcohol involvement in incidents attended by the police is limited due to a small number of studies, ${ }^{5,6}$ the limited amount of information about alcohol consumption that is collected by police, ${ }^{7}$ and by inconsistencies in police collection and recording of such information. ${ }^{5}$

\section{Program aim}

In response to these circumstances, the Alcohol Linking Program, a collaborative venture between Hunter New England Population Health, the University of Newcastle and NSW Police has been undertaken for more than a decade to improve community safety by enhancing the collection and recording by police of alcohol intelligence information, and by applying this information to reduce the harms associated with the excessive consumption of alcohol on licensed premises. ${ }^{8}$ This paper provides an overview of this program of research.

\section{The Alcohol Linking Program}

The Alcohol Linking Program involves police routinely gathering and recording the alcohol consumption characteristics of persons involved in police-attended incidents. This information describes whether the person consumed alcohol before the incident (observation or reported), their intoxication status (based on observation of behavioural signs), their last place of alcohol consumption (reported) and, if the last place was a licensed premises, the name and 
address of the premises. If a person was recorded as having consumed alcohol before the incident, the incident was considered to be 'alcohol-related'. If the person was recorded to have consumed alcohol at a particular licensed premises, the alcohol-related incident was considered to be 'linked' to that premises.

The Alcohol Linking Program specifically assessed the use of this intelligence information in an educative intervention delivered by police to licensed premises. The intervention involved police mailing to licencees a report that provided details of police-attended incidents reported to have followed consumption of alcohol on their premises. The report provided information regarding the type, time, date and place of each incident, and the alcohol and intoxication status of the person, and their age and gender. Those premises that were associated with such incidents were also the subject of a structured audit, conducted by police, of their responsible service of alcohol and management practices. The results of the audit were provided to licencees in a subsequent educative feedback visit.

\section{Efficacy of the Program}

The efficacy of this intelligence-based policing intervention was assessed in a randomised controlled trial involving all 398 licensed premises in the Hunter and Central Coast regions of NSW. Half of the premises were randomly allocated to receive the Alcohol Linking Program intervention (experimental group), and half were allocated to receive normal policing (control group). All experimental group premises received the mailed report, and those with at least one associated incident received the audit on one occasion. Police-recorded alcohol-related incidents associated with licensed premises were the outcomes of interest. The number of such incidents for three-month pre- and postintervention periods were compared for both groups of premises.

Over the three-month follow-up period, police-attended alcohol-related incidents associated with experimental group premises declined by $36 \%$ relative to the preintervention period, whereas such incidents associated with control group premises declined by $21 \%$, resulting in 61 fewer incidents associated with the experimental group premises. ${ }^{8}$

\section{Adoption of the Program into routine practice}

Based upon the positive outcomes of the efficacy study, a further trial was undertaken to determine the impact of the Program when adopted into routine policing practice. This pre-post trial was conducted with all 1400 licensed premises and all 2500 police in the Hunter Region and in Western NSW.

All licensed premises received the mailed report on three occasions, and approximately $8 \%$ of premises with the greatest number of 'linked' incidents received the audit on two occasions. Once again police-recorded alcoholrelated incidents associated with licensed premises were the outcomes of interest. The number of such incidents, pre- and postintervention, were compared for the trial area and a comparison area in NSW.

\section{Adoption strategies}

The adoption of the Program into routine policing practice involved the implementation of a multistrategic intervention to modify existing NSW Police infrastructure and procedures. The various strategies involved:

- gaining senior police leadership support for enhancement of police prevention of alcohol-related crime in general, and the Alcohol Linking Program in particular,

- modification of statewide police computing systems that mandated the standardised recording of data, and its collation and retrieval,

- face-to-face training of all police regarding the Program rationale and procedures and

- distribution to police of monthly reports regarding performance against agreed data collection and recording benchmarks.

The results demonstrated that up to 34000 incidents of alcohol-related crime occur each year in the trial area. Up to $69 \%$ of disorder offences were alcohol-related. In rural areas, police attended an alcohol-related incident approximately every 30 minutes. In urban areas, up to $60 \%$ of alcohol-related incidents followed consumption of alcohol on licensed premises. Not all premises were associated with such harm, with $30 \%$ of premises contributing to approximately $78 \%$ of all incidents associated with licensed premises. In some cases, single premises were associated with up to 190 incidents per year.

Over a three-month period, the number of people in the trial area who consumed alcohol before becoming involved in a police-attended incident decreased by approximately $10 \%$, compared with an increase of $6.7 \%$ in the comparison area. Based on these positive outcomes, the Program has subsequently been fully adopted into routine practice by all police in two jurisdictions (NSW Police and New Zealand Police).

Interpretation of the findings described above needs to be considered in the light of the limitations of using agencycollected data. These limitations include issues of consistency of police data recording, and in the case of this program of research, the use of self-report data as the basis for determining the success of the Program. Similarly, the interpretation of findings needs to be considered in the light of the use of a non-equivalent comparison area. 


\section{Implications for public health}

The outcomes of the Alcohol Linking Program have several implications for the health care system and the community more broadly. First, the findings demonstrate the extent of alcohol-related harm in the community and consequently, the need for a 'whole of community' response directed at its reduction. Second, the findings demonstrate the ability of health and public health practitioners to contribute to such a reduction. Further opportunities for such a contribution include, for example, the implementation of an equivalent surveillance system in emergency departments to identify the need for local community-based alcohol interventions. Public health staff can also contribute to reducing alcohol-related harm by taking a role in monitoring licencee compliance with the Liquor Act, as occurs in other jurisdictions, and occurs in NSW with respect to licencee compliance with Smoke Free legislation. Injury prevention, health promotion and drug and alcohol practitioners have the potential to contribute to enhancing the capacity of licencees to serve alcohol responsibly, to further enhancing police capacity and to enhancing community understanding of the need for responsible alcohol consumption more generally.

\section{Acknowledgements}

Throughout the past decade the Program has enjoyed the support of Hunter New England Health, NSW Police, NSW Health, NHMRC, University of Newcastle, Hunter Medical Research Institute, Alcohol Education and Rehabilitation Foundation and New Zealand Police.

\section{References}

1. Barbor TF, Caetano R, Casswell S, Edwards G, Giesbrecht N, Graham K, Grube JW, Grunewald P, Hill L, Holder HD. Alcohol: no ordinary commodity — research and public policy. Oxford: Oxford University Press, 2003.

2. Chikritzhs T, Catalano P, Stockwell T, Donath S, Ngo H, Young D, Matthews S. Australian alcohol indicators, 1990-2001: patterns of alcohol use and related harms for Australian states and territories. Perth: National Drug Research Institute, 2003.

3. NSW Department of Gaming and Racing. 1997 NSW Liquor Fee Analysis. Sydney: NSW Department of Gaming and Racing, 1997.

4. Lang E. Drinking locations of drink-drivers in the Perth Metropolitan area. In: Stockwell T, Lang E, Rydon P, editors. The licensed drinking environment: current research in Australia and New Zealand. Bentley: National Centre for the Prevention of Drug Abuse, 1991.

5. Ireland CS, Thommeny JL. The crime cocktail: licensed premises, alcohol and street offences. Drug Alcohol Rev 1993; 12: 143-50. doi:10.1080/09595239300185571

6. Briscoe S, Donnelly N. Temporal and regional aspects of alcohol-related violence and disorder. NSW: National Drug Research Institute of Curtin University and NSW Bureau of Crime Statistics and Research, 2001.

7. Doherty SJ, Roche AM. Best practice in policing licensed drinking environments: a monograph for police and policy makers. Adelaide: Australasian Centre for Policy Research, 2003.

8. Wiggers J, Jauncey M, Considine R, Daly J, Kingsland M, Purss K, Burrows S, Nicholas C, Waites RJ. Strategies and outcomes in translating alcohol harm reduction research into practice: the Alcohol Linking Program. Drug Alcohol Rev 2004; 23: 355-64. doi:10.1080/09595230412331289518 